\title{
The effect of internal and external focus of attention on game performance in tennis
}

\author{
Marina Tsetseli*, Eleni Zetou, Nikos Vernadakis, and Maria Michalopoulou \\ Department of Physical Education and Sport Sciences, Democritus University of Thrace, Komotini, Greece
}

Copyright: (C) 2016 M. Tsetseli et al. This is an open access article licensed under the Creative Commons Attribution License (http://creativecommons.org/licenses/by/4.0/).

\begin{abstract}
Background: Great importance has been given in recent years to the impact of focus of attention cues during skills execution but not during real game play, where more cognitive skills are involved besides technical performance. Objective: The purpose of the present study was to examine the effect of internal and external focus of attention instructions on the components of the game performance (decision making, skill execution, base) in tennis. Methods: The participants $(N=60)$ were divided into three groups and followed an intervention training program that lasted 6 weeks; IF group $(n=20)$ under internal focus of attention instructions, EF group $(n=20)$ under external focus of attention instructions and CON group $(n=20)$ under no attentional focus instructions. Three measurements took place (pre, post and ret) in which the participants were recorded on video while playing matches in real scoring conditions. Game Performance Assessment Instrument (GPAI) was used to evaluate the components of game performance in tennis in three game situations; service, return of the service, base line game. Results: ANOVA repeated measures in a 3 (groups: IF, EF \& CON) $\times 3$ (measurements: pre, post, ret) revealed a significant interaction between groups and measurements and post hoc analysis indicated that the group that was instructed to focus externally improved significantly only in decision making compared to the internal focus of attention and to the control group. The score difference was maintained at the retention test as well, which indicates that the impact concerned not only performance but also learning. Conclusions: Instructions that aim to an external focus of attention enhance decision making skills, which are considered the most important element of game performance in tennis.
\end{abstract}

Keywords: instructions, decision making, game understanding, tactical awareness, net game

\section{Introduction}

The importance of the effect of focus of attention on the performance of motor skills has concerned many scientists engaged in the study of human movement. The accuracy and quality of execution of skills strongly depend on where the athletes will focus their attention while performing a skill. Great significance should be considered to the fact that the attentional focus during motor execution not only affects performance and learning (Wulf, 2007a) but enhances movement effectiveness and efficiency as well (Wulf \& Lewthwaite, 2010). Singer et al. (1996) were the first who studied the effect of the focus of attention on performance and learning of complex motor skills. Their main findings were that the trainees, who were not aware of the technical characteristics of the motion executed, had better

\footnotetext{
* Address for correspondence: Marina Tsetseli, Department of Physical Education and Sport Sciences, Democritus University of Thrace, Komotini, Aisxylou 30, 17236 Athens, Greece. E-mail:mtsetsel@phyed.duth.gr
}

performance than those who had received instructions about the motor model. The following researchers defined the terms of internal focus of attention instructions as those which direct the performer's attention to the movement of the body executing the skill and the external focus of attention cues as those which lead the directing attention to the outcome of the motion executed (Wulf, Höß, \& Prinz, 1998). According to Wulf, Lauterbach, and Toole (1999) most coaches often use specific instructions to direct practitioners' attention to the movement of body parts in order to teach motor skills. The same researcher and her fellows, in a great number of studies (Chiviacowsky, Wulf, \& Wally, 2010; Jackson \& Holmes, 2011; Wulf, 2007b; Wulf, Landers, Lewthwaite, \& Tollner, 2009; Wulf, McConnel, Gartner, \& Schwarz, 2002; Wulf \& McNevin, 2003; Wulf, McNevin, Fuchs, \& Toole, 2000; Wulf, Mercer, McNevin, \& Guadagnoli, 2004; Wulf \& Prinz, 2001; Wulf, Shea, \& Matschiner, 1998; Wulf, Tollner, $\&$ Shea, 2007), proved on the other hand, that the performance of motor skills execution is better when the 
instructions given to the athletes guide them to focus away from their body movements compared with the cues aimed toward internal focus of attention. What is more interesting, and in contrast to other variables studied in the motor learning literature, is that a person's attentional focus often has a similar influence on both immediate performance and learning, which reflects a more permanent change in the capability to perform a skill (Wulf, 2013). According to the constrained action hypothesis (Wulf, McNevin, \& Shea, 2001) and the reinvestment theory (Masters \& Maxwell, 2008) instructions aiming to an external focus of attention lead to the production of more automatic movements since there is no conscious control intervention in contrast to the internal focus of attention providing instructions. In addition, when the attention is focused internally, then not only the automatic motor control procedure, which would normally regulate the movement, is constrained but the decision making as well, resulting in decreased performance (Masters \& Maxwell, 2008). On the other hand, external focus of attention cues are able to reduce the load of the working memory so the trainees use their decision making ability in order to select the most appropriate motor response (Poolton, Maxwell, Masters, \& Raab, 2006). Memmert and Furley (2007) tried to explore the link between breadth of attention and tactical decision-making and revealed that team players often fail to find the optimal tactical solution to a game situation because the coaches narrow their focus of attention by giving them restrictive instructions. Moreover, due to the fact that attention to visual information searching underlies the cognitive system (Gottlieb, 2012), some researchers tried to assess the link between vision and focus of attention. According to the results of object manipulation studies, in golf (Land, Tenenbaum, Ward, \& Marquardt, 2013) and dart throwing (Sherwood, Lohse, \& Healy, 2014), the superiority of the external focus of attention is not attributed to visual information processing during performing a motor skill. Similar, the research of Abdollahipour, Psotta, and Land (2016) revealed that the use of the external attentional focus does not rely on visual information even in a non-object manipulation action such as jumping height. Therefore, the present research hypothesizes that the potential benefits of the external focus of attention group are not due to the role of vision.

Finally, from a practical point of view, it is understood that the coaches' major concern is the game performance outcome. Despite the fact that their goal is to maximize their athletes' performance, they still ignore the cognitive skills needed to be practiced during training. Experience has shown that a well performed skill execution does not always have a successful outcome, and an incorrect executed movement skill does not always lead to minimized performance.

Thus, the present study aims to extend the existing research that supports the superiority of external focus of attention instructions for performance and learning of motor skills, by exploring whether external attentional focus has similar advantages to the simple individual tactics of young tennis players in real game situations. Taking into consideration that the main aspect of game performance is the recognition ability of the game strategy and the fact that tennis performance is the result of a) the use of possible motor responses that are relevant to the game situations and b) the skills execution ability the research aims to assess which type of focus of attention instructions has better impact on tennis game performance.

\section{Teaching tennis}

Tennis is an open skills sport performed in a changing and unpredictable environment, which imposes particular demands on perceptual and cognitive skills. The main difficulty in sports where athletes try to react to an opponent's stroke is that a decision must be taken in a very short time, the most correct type of stroke must be chosen and the selected skill must be executed as well as possible and as quickly as possible. Grehaigne, Godbout, and Bouthier (2001) contended that for an athlete to play well, means first to be able to choose the appropriate decision at the right time and in the right way and second to be able to repeat this cycle several times during a match. That means that young athletes must learn to watch, through the information elaboration that come through the sensors, and respond to external stimulus relevant to the execution of the movement and to ignore those that are unnecessary (Beilock, Bertenthal, McCoy, \& Carr, 2004; Ford, Hodges, \& Williams, 2005; Wulf et al., 1998). Finally, it is necessary to learn to focus their attention to information that is important for their one motor answer and to isolate the minor ones (Abernethy, 1993; Singer et al., 1996). Therefore, it is understood that the achievement of high performance is no longer only a matter of great virtuosic execution but is a matter mostly of a proper decision making. For this to happen, the young athletes have to learn gradually to simplify and to reduce the load between the incoming information and the elaboration of long-term working memory in order to select the reply and to respond to the motor incentive (Ericsson \& Kintsch, 1995). Of great importance to this procedure is the accumulated knowledge derived from the intensive practice in specific, for each sport, game situations. The most widespread method, concerning this purpose, is the "Teaching Games for Understanding" (Bunker \& Thorpe, 1983) that was 
later developed by Mitchell, Oslin, and Griffin (2006). This tactical approach method places first the "what to do" before the "how to do". That means that the role of the declarative knowledge ("what to do"), in the performing and learning environment, precedes the procedural knowledge ("how to do"). Therefore, if the instructions given from coaches to athletes, when performing a skill, lack of tactical knowledge then they will never acquire the necessary tactics to become competitive (Nevett, Rovegno, \& Babiarz, 2001). Teaching the sport of tennis to children means the necessity of teaching a range of the required technical skills and the momentousness of progressively introducing, at the same time, a series of tactical intensions. The sport's teaching should be based on the assumption that at any moment the player may be in one of the five following game situations: 1) serving, 2) returning, 3) baseline game, 4) approach or at the net and 5) pass and lob (Tennant, 2004). In each of these situations players must implement some specific tactics. For this reason, the purpose of the training process should be primarily focused on how the athletes will be able to manage and react to these situations. Thus, the training programs should now include methods that emphasize to the ability of the players to take effective decisions for responding to the incoming motor incentive. The technique based approach is a necessary form of teaching but by itself does not promote the effective learning of the tennis sport. On the other hand, the tactical approach demands from the players to solve problems encountered in the match. This can only be achieved through practicing the skills where the game situations will be combined with the tactical intensions. This form will lead eventually to a thorough understanding of the real character of the sport of tennis.

Concluding, the first and the main outcome of modern tennis practice should be teaching skills not through conscious motor control but through an implicit process, such as the tactical implementation of the skills. That means that a study, like the present one, is of great importance because it aims to assess the effect of external attention on game performance thoroughly. This is believed to produce significant knowledge, used by the coaches, for the development of young players. The study looked into the following main research hypothesis: athletes of external focus of attention group will have better results in Game Performance Assessment Instrument (GPAI) variables (decision-making, skills execution and base) and GPAI total score from athletes of internal focus of attention and control group in the post and retention test.

\section{Methods}

\section{Participants}

Sixty male and female tennis athletes, aged 8-9 years old $(M=8.4, S D=0.54)$, participated in the present study. All players had $1-2$ years $(M=1.5, S D=0.4)$ training experience. The athletes were randomly divided into three groups, the internal focus intervention group $(n=20)$, the external focus intervention group $(n=20)$ and the control group $(n=20)$. After obtaining permission from the Institutional Review Board of the University, participants were informed about the purpose of the study and the obligations for participation in the experiment. Before participating in this study, all athletes and their parents were fully informed about the procedure and written consent was obtained before testing. Athletes were informed that participation was voluntary and they could stop whenever they wanted.

\section{Intervention program}

The study was conducted in the "orange" court according to the International Tennis Federation rules for players 10 and under years old (International Tennis Federation, 2012). The dimensions of the shaped court were $18 \times 6.5 \mathrm{~m}$ and the height of the net was $80 \mathrm{~cm}$ (International Tennis Federation, 2012). The balls used were the Wilson low compression balls (50\% lower pressure than the normal balls) and the rackets used from the players were 25 inches size.

Theintervention programlasted 6 weeksandincluded 12 training sessions (2 practices/week $\times 6$ weeks). Each training session lasted 60 minutes in total. Each practice started with a 10 minute coordination based warm up followed by demonstration of each skill (forehand, backhand, service). The total practice time of the three skills was 20 minutes. This was followed by a competitive match consisting of 4 games, where no attentional instructions were given. The number of verbal attention cues given to the players was equal for each experimental group (five instructions), were similar in content and were provided at the beginning and then every five repetitions (Uehara, Button, \& Davids, 2008; Wulf et al., 2002). The players executed 10 strokes in each skill so the same instruction for each one skill was being given 2 times. The 2 experimental groups were given only attentional cues whilst the control group was given feedback while practicing the skills. Finally, great importance was given to the use of metaphoric phrases in the external attention group (Wulf, 2007a). The players were practiced under semi-predictable environment. A coach, standing at the service line at the opponents' court, was feeding the balls. Out of the 10 strokes the 5 were targeted to 
consistency (keep the ball in play) and 5 to building the point by aiming to targets in the court either cross or line (moving the opponent).

The internal attention group was given instructions that aimed to focus the attention of the players to their body movements (service: "Place your hand in the racket as if you feel you are holding a hammer", forehand: "Move your arm through the right foot and hit the ball in front of your left foot", backhand: "Point the target with your right shoulder") and the external attention group was given instructions that aimed to focus the attention of the players to the outcome of the movements executed (service: "Place your hand on the red mark on the grip", forehand: "Move your racket as you want to make a small circle and hit the ball in front of you", backhand: "Point the target with your racket face"). Participants of the control group received no attention instructions and practiced under the traditional teaching method where the augmented feedback from the coach was related to the technical elements of the skills (knowledge of performance). The internal and external focus of attention instructions for each skill are presented in Table 1.

Table 1

Internal and external focus of attention instructions for each skill

Internal attentional focus instructions
1. Place your hand in the racket as if you feel you are
holding a hammer.
2. Turn your body to the side and place your right foot
behind the left (the opposite for the left handed
players).
3. Lift your arm stretched in order to hit the ball.
4. Turn your wrist so your palm is facing the target.
5. Push off with your outside foot to make a cross step
and return to the center mark of the base line.

External attentional focus instructions

Service

1. Place your hand on the red mark on the grip (there was a red marked line on the grip of the racket).

2. Turn your body to the side and make the letter " $\mathrm{T}$ " with your feet.

3. Lift your arm up to the sky in order to hit the ball.

4. Turn your wrist so your racket is facing the target.

5. Push the ground with your outside foot to make a cross step and touch with your racket the center mark of the base line.

Forehand drive

1. Place your hand in the racket as if you feel you are making a handshake.

2. Stop in a comfortable position and feel the ground under your feet before you hit the ball.

3. Move your arm through the right foot and hit the ball in front of your left foot (the opposite for the left handed players).

4. Point the target with your left shoulder (the opposite for the left handed players).

5. Push off with your outside foot to make a cross step and return to the center mark of the base line.
1. Place your hand on the red mark on the grip (there was a red marked line on the grip of the racket).

2. Stop with both feet in a comfortable position before you hit the ball.

3. Move your racket as you want to make a small circle and hit the ball in front of you.

4. Point the target with your racket face.

5. Push the ground with your outside foot to make a cross step and touch with your racket the center mark of the base line.

Backhand drive

1. Place your two hands in the racket as if you feel that your right hand is holding a hammer and your left is making a hand shake (the opposite for the left handed players).

2. Stop in a comfortable position and feel the ground under your feet before you hit the ball.

3. Move your left arm through the left foot and hit the ball in front of your right foot (the opposite for the left handed players).

4. Point the target with your right shoulder (the opposite for the left handed players).

5. Push off with your outside foot to make a cross step and return to the center mark of the base line.
1. Place your hands on the marks on the grip (there was two red marked lines on the grip of the racket).

2. Stop with both feet in a comfortable position before you hit the ball.

3. Move your racket as you want to make a small circle and hit the ball in front of you.

4. Point the target with your racket face.

5. Push the ground with your outside foot to make a cross step and touch with your racket the center mark of the base line. 


\section{Procedure}

The athletes of all groups participated in three measurements; before the intervention program (pre) in order to confirm that there were no significant differences among the groups, after the completion of the intervention program (post) in order to note the effect of attentional instructions at each group and finally one week after the post-test, where the athletes had no practice, for ascertaining learning (ret). During these measurements the participants of each one of the three groups were video recorded while playing one short set match against each other (4 games; $3-3$ up to 5 games, 4-4 up to 7 points tie-break), according to the official competition scoring system proposed by the International Tennis Federation for players under 10 years old (International Tennis Federation, 2012). One wide angle lens digital video camera (Panasonic VDR-M30, Panasonic, Kadoma, Japan), based on tripod, was positioned 5 meters behind the right base line. The camera was set up on a 3 meters height chair umpire aiming to a 45 degree fixed shot. This position of the camera allowed for a full court clear shot, thus the recording of both players during the match at the same time. The participants of each group played matches based on a draw, so each one of them was video recorded and observed in one match. The approximately total amount of time video recording was $200 \mathrm{~min}$ for each group. The 10 minute coordination based warm up, the same as was held during the intervention program, also took place before every match started.

\section{Evaluation of game performance}

GPAI (Mitchell et al., 2006; Oslin, Mitchell, \& Griffin, 1998) was used to assess athletes' game performance in three time periods. One of the tool's benefits is that the criteria can be adapted and thus the observers may select any of the components or all of them according to each sport's needs (Hopper, 2007; Robinson \& Foran, 2011). In the present study the focus was on the three out of the five game situations in tennis because of the age and the level of the participants; service, return of the service and base line game (Tennant, 2004). Regarding these game situations, the proper game performance components decided for evaluation were decision-making, skills execution and base. These elements were selected because they are considered to be the foundation of the game performance in tennis since testimonials like cover and adjust come afterwards. Although cover has specific importance in a tennis match, it however derives first from the decision making and then the base. Adjust shows up later naturally, as the level of the athletes increases, through consistent and long skills practice where more physical characteristics of the incoming balls appear; height, depth, speed and spin. Therefore, in the current research where under 10 year old athletes were involved, these three components were assumed to be most necessary for evaluation. Decision making and skills execution are considered "on the ball components" while base is considered "off the ball component". The fact that GPAI is able to assess not only the "on the ball elements" but the "off the ball elements" as well is also a significant advantage (Mitchell et al., 2006). The definitions of the game performance components are presented in Table 2 and the assessment criteria are presented in Table 3. Finally, the scoring system of GPAI uses indexes for the individual components of performance and the sum of those indexes consists of the score of the game performance thoroughly. Specifically, Decisions Made Index $(\mathrm{DMI})=$ number of appropriate decisions made / number of inappropriate decisions made, Skill Execution Index $($ SEI $)=$ number of efficient skill executions / number of inefficient skill executions, Base Index $(\mathrm{BI})=$ number of appropriate supporting movements divided by number of inappropriate supporting movements and Game performance $=(\mathrm{DMI}+\mathrm{SEI}+\mathrm{BI}) / 3$.

Table 2

Components definitions

\begin{tabular}{|c|c|c|}
\hline Component & Definition & Criterion \\
\hline Decision making & $\begin{array}{l}\text { Making appropriate choices about what } \\
\text { to do with the ball (or projectile) } \\
\text { during the game. }\end{array}$ & $\begin{array}{l}\text { The athlete tries to "build" the point by moving the opponent either } \\
\text { with the service or the return of the service or with the forehand } \\
\text { and backhand during base line game. }\end{array}$ \\
\hline Skill execution & Efficient performance of selected skills. & $\begin{array}{l}\text { The athlete performs the skills (forehand, backhand, service, return } \\
\text { of the service) as efficiently as possible trying to implement the } \\
\text { decision he/she took. }\end{array}$ \\
\hline Base & $\begin{array}{l}\text { Appropriate return of performer to } \\
\text { a "home" or "recovery" position } \\
\text { between skill attempts. }\end{array}$ & $\begin{array}{l}\text { The athlete recovers to a base position at the base line after perform- } \\
\text { ing each skill. }\end{array}$ \\
\hline
\end{tabular}


Table 3

Assessment criteria - Game Performance Assessment Instrument

\begin{tabular}{|c|c|c|}
\hline Criterion & Factor & Appropriate/inappropriate \\
\hline $\begin{array}{l}\text { 1. Does the player place the service wide in order to move the } \\
\text { opponent away from the side line? }\end{array}$ & Decision making & \\
\hline 2. Is the service executed technically correct? & Skills execution & \\
\hline $\begin{array}{l}\text { 3. Does the player return on time in the ready position after the } \\
\text { service execution? }\end{array}$ & Base & \\
\hline $\begin{array}{l}\text { 4. Does the player play to the open court aiming to move the } \\
\text { opponent during base line game at his/her service game? }\end{array}$ & Decision making & \\
\hline $\begin{array}{l}\text { 5. Are forehands and backhands executed technically correct } \\
\text { during base line game at his/her service game? }\end{array}$ & Skills execution & \\
\hline $\begin{array}{l}\text { 6. Does the player return on time in the ready position after each } \\
\text { stroke execution at his/her service game? }\end{array}$ & Base & \\
\hline $\begin{array}{l}\text { 7. Does the player place the return of the service to the open } \\
\text { court aiming to move the opponent? }\end{array}$ & Decision making & \\
\hline 8. Is the return of the service executed technically correct? & Skills execution & \\
\hline $\begin{array}{l}\text { 9. Does the player return on time in the ready position after the } \\
\text { return of the service execution? }\end{array}$ & Base & \\
\hline $\begin{array}{l}\text { 10. Does the player play to the open court aiming to move the } \\
\text { opponent during base line game at the opponent's service } \\
\text { game? }\end{array}$ & Decision making & \\
\hline $\begin{array}{l}\text { 11. Are forehands and backhands executed technically correct } \\
\text { during base line game at the opponent's service game? }\end{array}$ & Skills execution & \\
\hline $\begin{array}{l}\text { 12. Does the player return on time in the ready position after each } \\
\text { stroke execution at the opponent's service game? }\end{array}$ & Base & \\
\hline
\end{tabular}

\section{Reliability of the observers}

Observation and evaluation was held by two expert tennis coaches who did not intrude on the experiment, as proposed by Memmert and Harvey (2008). The two observers were trained and practiced in using the assessment instrument according to the directions of the creators of the observation tool. They observed four videotapes and coded four athletes while they were playing one short set match of four games the first day and evaluated the same athletes the next day. The aim of the above procedure was the assurance of condition that the coders were able to perform reliable evaluation with the assessment instrument. The interobserver reliability using Cohen's kappa coefficient was .92 for decision making, .93 for skill execution, and .91 for base. Intra-observer reliability was .91 for decision making, .93 for skill execution and 0.92 for base and .97 for decision making, .98 for skill execution and .96 for base respectively, indicated strong agreement (Potrac, Jones, \& Cushion, 2007).

\section{Statistical analysis}

Prior to the repeated measures analysis of variance, distribution normality with Kolmogorov-Smirnov test (K-S test) and homogeneity of variance (Bartlett test) were carried out. Tests resulted in a non-significant value $(p<.05)$, which indicates that the data do not differ significantly from the multivariate normality of variables, thus parametric tests can be applied. One way analysis of variance for examining differences in pre-test between the groups was used. In order to find differences between groups, repeated measures ANOVA, Bonferroni post-hoc and paired $t$-test were used. Significant differences between the mean scores were tested at the .05 alpha levels. An effect size was computed for each analysis using the partial etasquared statistic $\left(\eta_{\mathrm{p}}^{2}\right)(.02=$ small, $.13=$ medium, and $.26=$ large effect) to access the practical significance of findings. IBM SPSS Statistics (Version 17 for Windows; IBM, Armonk, NY, USA) was used to conduct all statistical tests.

\section{Results}

\section{Initial measurements}

One-way ANOVA revealed that there were no significant differences among groups in the pre-test. The means and standard deviations for the score of GPAI in the pre-test are shown in Table 4. 


\section{Post and retention measurements}

\section{Decision making}

Repeated-measures analysis of variance was conducted to evaluate the hypothesis of the study. The results revealed that there was a significant main effect of group $F(2,57)=8.749, \eta_{p}^{2}=.235, p<.001$. There was also significant main effect of measurement $F(2,114)=12.186, \eta_{\mathrm{p}}^{2}=.176, \quad p<.001$, in decision making. The within subjects contrast analysis revealed that there were significant differences between pre and post scores and between pre and ret scores for three groups on the decision making. Paired samples $t$-test revealed significant differences from pre to post $t(19)=-4.465, p<.001$ and pre to ret $t(19)=-4.417$, $p<.001$ for the external focus group, no significant difference from pre to post $t(19)=-1.506, p=.148$ and pre to ret $t(19)=0.000, p>.99$ for internal focus group, and no significant differences from pre to post $t(19)=-0.224, p=.825$ and pre to $t(19)=-1.000$, $p=.330$ for the control group.
Post-hoc Bonferroni revealed significant mean differences in the decision making scores at post between the athletes of external $(M=2.8, S D=0.8)$ and internal focus of attention group $(M=1.6, S D=1.1)$ and athletes of external and control group $(M=1.1, S D=1.1)$, but there were not differences between athletes of internal focus of attention and athletes of control group. The same results were also for the retention test; the athletes of external focus of attention were better than the athletes of two other groups. Therefore the results agree with the null hypothesis. The mean scores and standard deviations of each group across the three measurements are presented in Table 5.

\section{Skills execution}

Repeated-measures analysis of variance revealed that there was a significant main effect of group $F(2,57)=4.930, \quad \eta_{p}^{2}=.147, \quad p=.011$ and interaction effect between the group and the measurement $F(4,114)=4.103, \eta_{\mathrm{p}}^{2}=.126, p=.005$. There

Table 4

Performance scores (presented as $M \pm S D$ ) for each group and the results of analysis of variance in pre-test

\begin{tabular}{lcccccc}
\hline & Count & $\begin{array}{c}\text { Internal focus } \\
\text { of attention }\end{array}$ & $\begin{array}{c}\text { External focus } \\
\text { of attention }\end{array}$ & Control group & $F$ & $p$ \\
\hline Decision making & 20 & $1.2 \pm 1.1$ & $1.2 \pm 1.3$ & $1.1 \pm 1.3$ & 0.09 & .91 \\
Skills execution & 20 & $2.0 \pm 1.0$ & $2.1 \pm 1.4$ & $2.0 \pm 1.1$ & 0.10 & .89 \\
Base & 20 & $1.4 \pm 0.8$ & $1.4 \pm 0.8$ & $1.6 \pm 0.8$ & 0.39 & .69 \\
Total game performance & 60 & $4.6 \pm 1.6$ & $4.8 \pm 2.5$ & $4.7 \pm 2.6$ & 0.11 & .89 \\
\hline
\end{tabular}

Table 5

Performance scores (presented as $M \pm S D$ ) for each group in pre-, post- and retention tests

\begin{tabular}{lcccc}
\hline & Pre-test & Post-test & Retention test & Total \\
\hline Decision making & & & & \\
$\quad$ Internal focus of attention & $1.2 \pm 1.1$ & $1.6 \pm 1.1$ & $1.2 \pm 1.1$ & $1.1 \pm 1.2$ \\
$\quad$ External focus of attention & $1.2 \pm 1.3$ & $2.8 \pm 0.8$ & $2.7 \pm 0.7$ & $1.9 \pm 1.2$ \\
$\quad$ Control group & $1.1 \pm 1.3$ & $1.1 \pm 1.1$ & $1.2 \pm 1.3$ & $1.7 \pm 1.3$ \\
Skills execution & & & & \\
$\quad$ Internal focus of attention & $2.0 \pm 1.0$ & $2.4 \pm 1.4$ & $2.0 \pm 1.1$ & $2.0 \pm 1.2$ \\
External focus of attention & $2.4 \pm 1.0$ & $3.4 \pm 0.6$ & $2.0 \pm 0.7$ & $2.6 \pm 0.9$ \\
$\quad$ Control group & $2.8 \pm 1.2$ & $2.0 \pm 0.7$ & $2.2 \pm 0.8$ & $2.7 \pm 1.0$ \\
Base & & & & \\
$\quad$ Internal focus of attention & $1.4 \pm 0.8$ & $2.8 \pm 0.9$ & $1.6 \pm 0.8$ & $1.5 \pm 0.8$ \\
$\quad$ External focus of attention & $2.8 \pm 1.3$ & $3.9 \pm 0.3$ & $2.7 \pm 1.2$ & $3.1 \pm 1.1$ \\
$\quad$ Control group & $2.6 \pm 1.1$ & $2.7 \pm 0.4$ & $2.2 \pm 0.8$ & $2.9 \pm 1.1$ \\
Total game performance & & & & \\
$\quad$ Internal focus of attention & $4.6 \pm 1.6$ & $6.9 \pm 2.5$ & $4.7 \pm 2.6$ & $4.7 \pm 2.2$ \\
$\quad$ External focus of attention & $6.9 \pm 1.7$ & $10.1 \pm 0.9$ & $5.9 \pm 2.0$ & $7.6 \pm 2.4$ \\
$\quad$ Control group & $6.6 \pm 1.6$ & $5.9 \pm 1.2$ & $5.6 \pm 1.6$ & $7.3 \pm 2.3$ \\
\hline
\end{tabular}


was also significant main effect of measurement $F(2,114)=14.716, \eta_{\mathrm{p}}^{2}=.205, p<.001$, in skills execution. The within subjects contrast analysis revealed that there were significant differences between pre and post scores and between pre and ret scores for three groups on the skills execution. Paired samples $t$-test revealed no significant difference from pre to post $t(19)=-2.015$, $p=.058$ and pre to ret test $t(19)=-1.584, p=.130$ for the external focus group, significant differences from pre to post $t(19)=-4.194, p<.001$ and pre to ret $t(19)=0.567, p=.030$ for internal focus group, and no significant differences from pre to post $t(19)=-0.237$, $p=.815$ and pre to ret $t(19)=-0.721, p=.479$ for the control group.

Post-hoc Bonferroni revealed no significant mean differences at post in the skill execution scores between the athletes of external $(M=3.4, S D=0.6)$ and internal focus of attention group $(M=2.4, S D=1.4)$ and internal and control group $(M=2.0, S D=0.7)$, but there were significant differences between athletes of external focus of attention and athletes of control group. The same results were for the retention test; the athletes of external focus of attention were better than the athletes of the control group but they were not better than the athletes of the internal group. No significant difference was revealed between the athletes of internal and control group. Therefore the results did not agree with the null hypothesis. The mean scores and standard deviations of each group across the three measurements are presented in Table 5.

\section{Base}

A repeated-measures analysis of variance revealed that there was a significant main effect of group $F(2,57)=9.724, \quad \eta_{\mathrm{p}}^{2}=.254, \quad p<.001$ and interaction effect between the group and the measurement $F(4,114)=9.147, \eta_{\mathrm{p}}^{2}=.243, p<.001$. There was also significant main effect of measurement $F(2,14)=95.508$, $\eta_{\mathrm{p}}^{2}=.626, p<.001$ in base. The within subjects contrast analysis revealed that there were significant differences between pre and post scores and between pre and ret scores for three groups on the base. Paired samples $t$-test revealed significant difference from pre to post $t(19)=-5.659, p<.001$ and pre to ret test $t(19)=-4.857, p<.001$ for the external focus group, significant difference from pre to post $t(19)=-10.971$, $p<.001$ and pre to ret test $t(19)=-10.790, p<.001$ for the internal focus group, and significant differences from pre to post $t(19)=-4.067, p=.001$ and pre to ret $t(19)=-2.449, p=.024$ for the control group.

Post-hoc Bonferroni revealed no significant mean differences at post in the base scores between the athletes of external $(M=3.9, S D=0.3)$ and internal focus of attention group $(M=2.8, S D=0.9)$ and internal and control group $(M=2.7, S D=0.4)$, but there were significant differences between athletes of external focus of attention and athletes of the control group. The same results were for the retention test, where the athletes of external focus of attention were better than the athletes of the control group but there were not better than the athletes of the internal group. No significant difference was also revealed between the athletes of the internal and the control group. Therefore the results did not agree with the null hypothesis. The mean scores and standard deviations of each group across the three measurements are presented in Table 5.

\section{Game performance}

A repeated-measures analysis of variance revealed that there was a significant main effect of group $F(2,57)=20.715, \quad \eta_{\mathrm{p}}^{2}=.421, \quad p<.001$ and interaction effect between the group and the measurement $F(4,14)=14.769, \eta_{\mathrm{p}}^{2}=.341, p<.001$ on total score of performance. There was also significant main effect of measurement $F(2,114)=80.449, \eta_{\mathrm{p}}^{2}=.585, p<.001$ in game performance. The within subjects contrast analysis revealed that there were significant differences between pre and post scores and between pre and ret scores for three groups on the game performance. Paired samples $t$-test revealed significant difference from pre to post $t(19)=-9.424, p<.001$ and pre to ret test $t(19)=-10.137, p<.001$ for the external focus group, significant difference from pre to post $t(19)=-5.205$, $p<.001$ and pre to ret $t(19)=-4.254, p<.001$ for the internal focus group, and also significant differences from pre to post $t(19)=-9.424, p<.001$ and pre to ret test $t(19)=-10.137, p<.001$ for the control group.

Post-hoc Bonferroni revealed no significant mean differences at post in the total of game performance scores between the athletes of external $(M=10.1$, $S D=0.9)$ and internal focus of attention group $(M=6.9, S D=2.5)$ and between the internal and the control group $(M=5.9, S D=1.2)$ and there were significant differences between athletes of external focus of attention and athletes of the control group. The same results were for the retention test, the athletes of external focus of attention were better than the athletes of the control group but they were not better than the athletes of the internal group. No significant difference was also revealed between the athletes of the internal and the control group. Therefore the results did not agree with the null hypothesis. The mean scores and standard deviations of each group across the three measurements are presented in Table 5. 


\section{Discussion}

The purpose of the present study was to examine the effect of the internal and external focus of attention instructions on the game performance in real match situations at 8-9 year old tennis players. The main research hypothesis was that the athletes of the external focus of attention group would have better results in GPAI's variables (decision-making, skills execution and base) and GPAI total score from athletes of internal focus of attention and control group in the post and retention measurement. The data analysis revealed a significant improvement of the athletes of the group that was instructed to an external focus of attention in decision making compared to the athletes of internal focus group and to the control group as well. Considering the other two components of game performance, skill execution and base, the external attention group had better results than the control group but not than the internal attention group, at both post and retention tests. Finally, no significant differences were revealed between the internal focus and the control group, in any aspect of game performance. The finding that both experimental groups had no significant differences between them in skills execution, although both of them improved significantly their scores from the initial to the final measurement, is obviously due to the fact that the internal focus group was practiced under technical instructions resulting in improvement at the performance of the skills. Regarding base, the most rational explanation for the non-existent differences between external and internal focus groups is the absence of the feedback during post measurement for the EF group, since it has been, by experience, noticed that tennis players at these ages depend strongly on the frequent feedback that guides them to recover at the middle of the court after a skill execution. At last, considering the fact that the control group mirrored the internal attention group may be an indication that the athletes of the control group had probably developed their own natural internal focus through past training, which was likely orientated to technique performance.

The superiority of the external focus of attention instructions has been proved by previous studies examining object manipulation skills. Results of researches in the field of volleyball (Wulf et al., 2002), basketball (Al-Abood, Bennet, Hernandez, Ashford, \& Davids, 2002; Zachry, Wulf, Mercer, \& Bezodis, 2005), golf (Bell \& Hardly, 2009; Wulf \& Su, 2007; Wulf et al., 1999), discus throwing (Zarghami, Saemi, \& Fathi, 2012), dart throwing (Marchant, Clough, \& Crawshaw, 2007; Marchant, Clough, Crawshaw, \& Lery, 2009; McKay \& Wulf, 2012; Schorer, Jaitner, Wollny, Fath, \& Baker, 2012), tennis (Maddox, Wulf, \& Wright,
1999; Wulf et al., 2000), soccer (Abdollahipour, Bahram, Shafizadeh, \& Khalaji, 2008; Wulf, Chiviacowsky, Schiller, \& Ávila, 2010), and baseball (Castaneda \& Gray, 2007) successfully lead to the above conclusion. However, the impact of attentional cues at these studies concerned mainly adult participants. The assessment of the correlation between attentional focus and learning during childhood is met in fewer researches. According to Abdollahipour et al. (2008), the external focus of attention instructions were superior regard to the time execution of a soccer dribbling task under stressful conditions in boys between 8 and 14 years old. In addition, external focus of attention improved the postural stability of children aged 4 to 11 years (Olivier, Palluel, \& Nougier, 2008) and meliorated the accuracy of a throwing skills in 12 years old children with mild mental deficiency (Chiviacowsky, Wulf, \& Ávila, 2012). Finally, the enhancement of learning of the forward truck roll 7-8 years old primary school kids was demonstrated when the provided cues aimed to external focus of attention (Koufou, Avgerinos, \& Michalopolou, 2013).

In the above mentioned studies, performance and learning were determined by assessing the movement outcome by means of accuracy, speed and distance. Regard to decision making, Memmert and Furley (2007) concluded, through their research, that a wide focus of attention is important for enabling junior players to see many opportunities in a sports environment. Considering the findings of the current study, that showed supremacy of the group that guided to focus externally in decision making, it is essential to analyse the connection between attentional focus and cognitive effects. Decision making can be understood and explained by the significant role of the perception skill (Williams, Davids, Burwitz, \& Williams, 1994). The main differences between novice and expert athletes concern the recognition and identification of environmental information, the decision on which response will be selected and the automatic execution of the movement (Schmidt \& Wrisberg, 2000). Thus, it has become evident that, during the "road to expertise", the amount of attention which needs to be dedicated to programming is being gradually decreased (William, Davids, \& Williams, 1999). According to some studies (Schmidt \& Lee, 2000; Schmidt \& Wrisberg, 2000) the technical coaching method often reduce the attention demands by separating the teaching of technical skills and the implementation of the tactics. The above researchers stated that once the learners have reached to the autonomous stage of skills acquisition, where the skill can be executed sufficiently and automatically, then they are able to learn basic tactic patterns and that those skills that they have mastered will be transferable 
to game situations. However, this tedious classic technique training seems to provide a non-understanding of the real aspects of the sport being learned and dissatisfaction especially when junior players are involved. On the other hand the tactical base approach also intends to reduce the load of attention needed, by giving priority to the teaching of simple tactics formats and by simplifying the technique characteristics. The aim of this approach is the development of basic decision making skills. Once this happens then the players can deal with more technique features. Holt, Ward, and Wallhead (2006) suggested that, during a tactic oriented method, the developed techniques are more flexible and for that reason is more likely these skills to be transferred and applied in game situations. Similar, the studies of Gray and Sproule (2011) as well as of Lee and Ward (2011) highlighted the role of the tactical model of instruction to the easy transfer of the necessary skills to real competitive conditions.

\section{Implementation in tennis}

Until recently the development of young tennis players relied on the learning of technique itself. This resulted in producing athletes that lacked tactical knowledge and demonstrated deficient ability to make decisions (Unierzyski \& Crespo, 2007). Moreover, studies undertaken by the International Tennis Federation showed that tennis "appeared not to be a fun game to learn and play for the vast majority of youngsters interviewed" (International Tennis Federation, 1998). Strean and Holt (2000) stated, through their research, that children, parents and coaches acknowledged that games and game-like situations were funnier than the technically oriented drills. However, applying the tactical approach does not automatically mean the abolishment of the technical one. Crespo and Reid (2003) claimed that a good level of executing technical skills is necessary for an effective implementation of tactics in tennis sport. That means that the technical development is the same important as before but it is no longer considered as the only and the main way for the tennis players to be effective and competitive. The game based approach method uses the biomechanical features of movement as a very useful tool for players to solve tactical problems. More specific, real tennis coaching process has proved that the quality of the total performance can be improved through combined training formats. The most useful way for enhancing both technical and tactical skills more easy, fast and effective is the "tactic-skill-tactic" tennis procedure known as open-closed-open (Pankhurst, 1999) or global-analyticglobal (Meier, 1999).

\section{Limitations of the study}

The concern that a percentage of the participants may have received practice under tactical approach method before the study was conducted was tried to be avoided by the selection of athletes from tennis clubs where the main training method followed was the technical development. Moreover, the number of the athletes which participated in the research came from an urban area since no player from any other county joined in the study. Thus, the results can be generalized to other young Greek tennis players, but should be interpreted with caution.

\section{Conclusion}

To sum up, it is understood that the use of internal focus of attention instructions and the use of external focus of attention instructions, should be important and integral parts of the teaching tennis process. According to the results of the present study using cues that guide attention externally enhances decision making at young tennis players $8-9$ years old. Due to this finding tennis coaches should be aware of the learning methods that have impact not only on the technique development but on the cognitive development as well, in order the players to be able to solve problems during the game. Our results provide initial indications that an internal focus of attention should be avoided with regard to minimizing cognitive deficits in tennis.

\section{Conflict of interest}

There were no conflicts of interest.

\section{References}

Abdollahipour, R., Bahram, A., Shafizadeh, M., \& Khalaji, H. (2008). The effects of attentional focus strategies on the performance and learning of soccer-dribbling task in children and adolescents. Journal of Movement Sciences and Sports, 1, 83-92.

Abdollahipour, R., Psotta, R., \& Land, W. M. (2016). The influence of attentional focus instructions and vision on jump height performance. Research Quarterly for Exercise and Sport, 87, 408-413.

Abernethy, B. (1993). Searching for the minimal essential information for skilled perception and action. Psychological Research, 55, 131-138.

Al-Abood, S. A., Bennet, S. J., Hernandez, F. M., Ashford, D., \& Davids, K. (2002). Effect of verbal instructions and image size on visual search strategies in basketball free throw shooting. Journal of Sports Sciences, 20, 271-278. 
Beilock, S. L., Bertenthal, B. I., McCoy, A. M., \& Carr, T. H. (2004). Haste does not always make waste: Expertise, direction of attention, and speed versus accuracy in performing sensorimotor skills. Psychonomic Bulletin \& Review, 11, 373-379.

Bell, J. J., \& Hardy, J. (2009). Effect of attentional focus on skilled performance in golf. Journal of Applied Sport Psychology, 21, 163-177.

Bunker, D., \& Thorpe, R. (1983). A model for the teaching of games in secondary schools. Bulletin of Physical Education, 19, 32-35.

Castaneda, B., \& Gray, R. (2007). Effects of focus of attention on baseball batting performance in players of differing skill levels. Journal of Sport and Exercise Psychology, 29, 60-77.

Chiviacowsky, S., Wulf, G., \& Ávila, L. T. G. (2012). An external focus of attention enhances motor learning in children with intellectual disabilities. Journal of Intellectual Disability Research, 57, 627-634.

Chiviacowsky, S., Wulf, G., \& Wally, R. (2010). An external focus of attention enhances balance learning in older adults. Gait \& Posture, 32, 572-575.

Crespo, M., \& Reid, M. (2003). Biomechanics and teaching methodology. In B. Elliott, M. Reid, \& M. Crespo (Eds.), Biomechanics of advanced tennis (pp. 13-30). London, United Kingdom: International Tennis Federation.

Ericsson, K. A., \& Kintsch, W. (1995). Long-term working memory. Psychological Review, 102, 211-245.

Ford, P., Hodges, N. J., \& Williams, A. M. (2005). Online attentional-focus manipulations in a soccer-dribbling task: Implications for the proceduralization of motor skills. Journal of Motor Behavior, 37, 386-394.

Gottlieb, J. (2012). Attention, learning and the value of information. Neuron, 76, 281-295.

Gray, S., \& Sproule, J. (2011). Developing pupils' performance in team invasion games. Physical Education \& Sport Pedagogy, 16, 15-32.

Grehaigne, J. F., Godbout, P., \& Bouthier, D. (2001). The teaching and learning of decision making in team sports. Quest, 53, 59-76.

Holt, J. E., Ward, P., \& Wallhead, T. L. (2006). The transfer of learning from play practices to game play in young adult soccer players. Physical Education and Sport Pedagogy, 11, 101-118.

Hopper, T. (2007). Teaching tennis with assessment "for" and "as" learning: A TGfU net/wall example. Physical and Health Education Journal, 73(3), 22-28.

International Tennis Federation. (1998). Tennis towards 2000. London, United Kingdom: Author.

International Tennis Federation. (2012). ITF rules of tennis. London, United Kingdom: Author.

Jackson, B. H., \& Holmes, A. M. (2011). The effects of focus of attention and task objective consistency on learning a balance task. Research Quarterly for Exercise and Sport, 82, 574-579.

Koufou, N., Avgerinos, A. G., \& Michalopoulou, M. (2013). An external focus of attention enhances forward roll learning in elementary school children during physical education classes. The Cyprus Journal of Sciences, 11, 21-32.

Land, W. M., Tenenbaum, G., Ward, P., \& Marquardt, C. (2013). Examination of visual information as a mediator of external focus benefits. Journal of Sport and Exercise Psychology, 35, 250-259.

Lee, M., \& Ward, P. (2011). Generalization of tactics in tag rugby from practice to games in middle school physical education. Physical Education \& Sport Pedagogy, 14, 189-207.

Maddox, M. D., Wulf, G., \& Wright, D. L. (1999). The effect of an internal vs. external focus of attention on the learning of a tennis stroke. Journal of Exercise Psychology, 21, 78.

Marchant, D. C., Clough, P. J., \& Crawshaw, M. (2007). The effects of attentional focusing strategies on novice dart throwing performance and their task experiences. International Journal of Sport and Exercise Psychology, 5, 291-303.

Marchant, D. C., Clough, P. J., Crawshaw, M., \& Levy, A. (2009). Novice motor skill performance and task experience influenced by attentional focusing instructions and instruction preferences. International Journal of Sport and Exercise Psychology, 7, 488-502.

Masters, R. S. W., \& Maxwell, J. P. (2008). The theory of reinvestment. International Review of Sport and Exercise Psychology, 1, 150-184.

McKay, B., \& Wulf, G. (2012). A distal external focus enhances novice dart throwing performance. International Journal of Sport and Exercise Psychology, 10, 149-156.

Meier, M. (1999). The GAG method. ITF Coaches Review, 19, 15.

Memmert, D., \& Furley, P. (2007). "I spy with my little eye”: Breadth of attention, inattentional blindness, and tactical decision making in team sports. Journal of Sport \& Exercise Psychology, 29, 365-381.

Memmert, D., \& Harvey, S. (2008). The Game Performance Assessment Instrument (GPAI): Some concerns and solutions for further development. Journal of Teaching in Physical Education, 27, 220-240.

Mitchell, S. A., Oslin, J. L., \& Griffin, L. L. (2006). Teaching sport concepts and skills: A tactical games approach (2nd ed.). Champaign, IL: Human Kinetics.

Nevett, M., Rovegno, I., \& Babiarz, M. (2001). Fourth-grade children's knowledge of cutting, passing and tactics in invasion games after a 12 lesson unit of instruction. Journal of Teaching in Physical Education, 20, 389-401.

Olivier, I., Palluel, E., \& Nougier, V. (2008). Effects of attentional focus on postural sway in children. Experimental Brain Research, 185, 341-345.

Oslin, J., Mitchell, S., \& Griffin, L. (1998). The Game Performance Assessment Instrument (GPAI): Development and preliminary validation. Journal of Teaching in Physical Education, 2, 213-243.

Pankhurst, A. (1999). Game based coaching. ITF Coaches Review, 19, 11-13.

Poolton, J. M., Maxwell, J. P., Masters, R. S. W., \& Raab, M. (2006). Benefits of an external focus of attention: Common coding or conscious processing? Journal of Sports Sciences, 24, 89-99.

Potrac, P., Jones, R., \& Cushion, C. (2007). Understanding power and the coach's role in professional English soccer: A preliminary investigation of coach behavior. Soccer \& Society, 8, 33-49.

Robinson, D. B., \& Foran, A. (2011). Pre-service physical education teachers' implementation of "TGfU Tennis": An 
assessment of upper elementary students' learning using the GPAI. PHENex Journal/Revue phénEPS, 3(2), 1-19.

Schmidt, R. A., \& Lee, T. D. (2000). Motor control and learning: A behavioral emphasis (3rd ed.). Champaign, IL: Human Kinetics.

Schmidt, R. A., \& Wrisberg, C. A. (2000). Motor learning and performance: A problem based learning approach (2nd ed.). Champaign, IL: Human Kinetics.

Schorer, J., Jaitner, T., Wollny, R., Fath, F., \& Baker, J. (2012). Influence of varying focus on attention conditions on dart throwing performance in experts and novices. Experimental Brain Research, 217, 287-297.

Sherwood, D. E., Lohse, K. R., \& Healy, A. F. (2014). Judging joint angles and movement outcome: Shifting the focus of attention in dart-throwing. Journal of Experimental Psychology: Human Perception and Performance, 40, 1903-1914.

Singer, R. N., Cauraugh, J. H., Chen, D., Steinberg, G. M., Frehlich, S. G., \& Wang, L. (1996). Visual search, anticipation and reactive comparisons between highly-skilled and beginning tennis players. Journal of Applied Sport Psychologist, 8, 9-25.

Strean, W. B., \& Holt, N. L. (2000). Players', coaches', and parents' perceptions of fun in youth sport. Avante, 6, 84-98.

Tennant, M. (2004). The five game situations in mini-tennis. ITF Coaching \& Sport Science Review, 32, 7-9.

Uehara, L. A., Button, C., \& Davids, K. (2008). The effects of focus of attention instructions on novices learning soccer chip. Brazilian Journal of Biometricity, 2, 63-77.

Unierzyski, P., \& Crespo, M. (2007). Review of modern teaching methods for tennis. International Journal of Sport Science, 3, 1-10.

Williams, A. M., Davids, K., Burwitz, L., \& Williams, J. G. (1994). Visual search strategies of experienced and inexperienced soccer players. Research Quarterly for Exercise and Sport, 5, 127-135.

Williams, A. M., Davids, K., \& Williams, J. G. (1999). Visual perception and action in sport. New York, NY: Taylor \& Francis.

Wulf, G. (2007a). Attentional focus and motor learning: A review of 10 years of research. E-Journal Bewegung und Training, 1, 4-14.

Wulf, G. (2007b). Attention and motor skill learning. Champaign, IL: Human Kinetics.

Wulf, G. (2013). Attentional focus and motor learning: A review of 15 years. International Review of Sport and Exercise Psychology, 6, 77-104.

Wulf, G., Chiviacowsky, S., Schiller, E., \& Ávila, L. T. (2010). Frequent external focus feedback enhances learning. Frontiers in Psychology, 1, 190.
Wulf, G., Höß, M., \& Prinz, W. (1998). Instructions for motor learning: Differential effects of internal versus external focus of attention. Journal of Motor Behavior, 30, 169-179.

Wulf, G., Landers, M., Lewthwaite, R., \& Töllner, T. (2009). External focus instruction reduce postural instability in individuals with Parkinson disease. Physical Therapy, 89, 162-168.

Wulf, G., Lauterbach, B., \& Toole, T. (1999). The learning advantages of an external focus of attention in golf. Research Quarterly for Exercise and Sport, 70, 120-126.

Wulf, G., \& Lewthwaite, R. (2010). Effortless motor learning? An external focus of attention enhances movement effectiveness and efficiency. In B. Bruya (Ed.), Effortless attention: A new perspective in the cognitive science of attention and action (pp. 75-101). Cambridge, MA: MIT Press.

Wulf, G., McConnel, N., Gartner, M., \& Schwarz, A. (2002). Enhancing the learning of sports skills through external focus feedback. Journal of Motor Behaviour, 34, 171-182.

Wulf, G., \& McNevin, N. H. (2003). Simply distracting learners is not enough. More evidence for the learning benefits of an external focus of attention. European Journal of Sport Science, 3, 1-13.

Wulf, G., McNevin, N., Fuchs, T., \& Toole, T. (2000). Attention focus in complex motor skill learning. Research Quarterly for Exercise and Sport, 71, 229-239.

Wulf, G., McNevin, N. H., \& Shea, C. H. (2001). The automaticity of complex motor skill learning as a function of attentional focus. Quarterly Journal of Experimental Psychology, 54, 1143-1154.

Wulf, G., Mercer, J., McNevin, N. H., \& Guadagnoli, M. A. (2004). Reciprocal influences of attentional focus on postural and supra-postural task performance. Journal of Motor Behavior, 36, 189-199.

Wulf, G., \& Prinz, W. (2001). Directing attention to movement effects enhances learning: A review. Psychonomic Bulletin \& Review, 8, 648-660.

Wulf, G., Shea, C. H., \& Matschiner, S. (1998). Frequent feedback enhances complex motor skill learning. Journal of Motor Behavior, 30, 180-192.

Wulf, G., \& Su, J. (2007). An external focus of attention enhances golf shot accuracy in beginners and experts. Research Quarterly for Exercise and Sport, 78, 384-389.

Wulf, G., Tollner, T., \& Shea, C. H. (2007). Attentional focus effects as a function of task difficulty. Research Quarterly for Exercise and Sport, 78, 257-264.

Zachry, T., Wulf, G., Mercer, J., \& Bezodis, N. (2005). Increased movement accuracy and reduced EMG activity as a result of adopting an external focus of attention. Brain Research Bulletin, 67, 304-309.

Zarghami, M., Saemi, E., \& Fathi, I. (2012). External focus of attention enhances discus throwing performance. Kinesiology, 44, 47-51. 